\title{
THE INFLUENCE OF MORTALITY FOCUS ON GUILT ADVERTISING EFFECTIVENESS
}

Nikki Wingate, Ph.D. Ernest C. Trefz School of Business University of Bridgeport
JaeYun Moon, Ph.D.

School of Business

Korea University
Mousumi Bose, Ph.D.

Dolan School of Business

Fairfield University

\begin{abstract}
The current research examined the influence of mortality focus on the effectiveness of guilt advertising via two experiments.

Mortality focus and type of guilt advertising appeal interacted such that directing the focus of mortality on one's own death (vs. other) facilitated effectiveness of guiltlessening (vs. guilt-magnifying) appeals.

The mediators of the influences were the motivation to boost self-

confidence (vs. manage impression).

The findings contribute to the literatures on consumer guilt, mortality salience, and defensive processing, while offering practical implications for guilt advertising management.
\end{abstract}

\section{Mortality Focus and Guilt Advertising}

Imagine you saw a program on TV that made you think about death, and subsequently you watched some commercials.

Which commercial would induce higher purchase intentions: a commercial for a college fund for your children, or one for a spa massage to pamper yourself?

Processing such commercials while influenced by thoughts of mortality may intertwine with feelings of guilt triggered by considering consumption of the object advertised. The nature of the guilt triggered is different in each commercial: the former triggers guilt related to not adequately supporting someone you are responsible for, and the latter triggers guilt regarding selfindulgent consumption.

\section{Conceptual Framework}

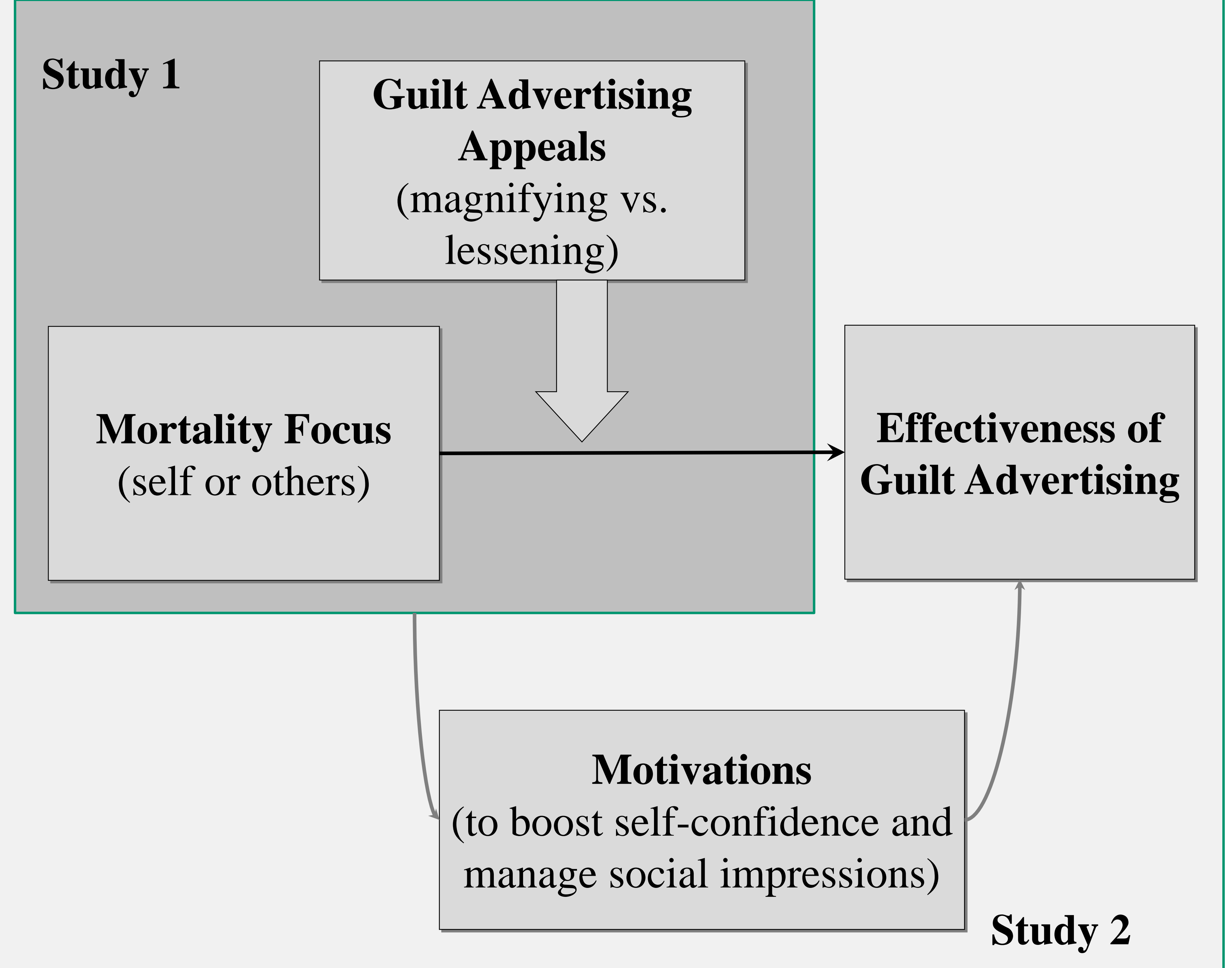

